\title{
History of the urban environmental imprint: introduction to a multidisciplinary approach to the long-term relationships between Western cities and their hinterland
}

\author{
Gilles Billen · Josette Garnier • Sabine Barles
}

Received: 29 February 2012/ Accepted: 1 March 2012/Published online: 14 March 2012

(C) Springer-Verlag 2012

\begin{abstract}
This paper introduces a series of 11 studies on the relationships between large Western cities (Paris, London, Brussels, Vienna, Barcelona, Athens, New York, Providence) and their surrounding territories over a long historical time period. The concept of hinterland is introduced to designate a rural territory structured by its function of supplying the city with food, fuel, water and other material. The papers question the usefulness of this concept in the current globalized world, where cities are often considered as simple nodes of a network of worldwide trade exchanges, but where new citizen aspirations for reconnecting urban and rural territories are emerging.
\end{abstract}

Keywords Urban imprint · Hinterland · Food supply · Energy · Drinking water supply

\section{Introduction}

What makes a city unique, and gives it its identity, is its centuries-long inhabited area superimposed with traces left by the population's changing activities. Sigmund Freud (1930) used the metaphor of the city of Rome, where monuments of over one millennium coexist with the modern infrastructures, to depict the geography of the human mind and its everlasting memories. The multiplicity of such imprints characterises the impact of a city on its environment. But the traces of activity are not limited to

G. Billen $(\bowtie) \cdot$ J. Garnier

UMR Sisyphe, UPMC/CNRS, Paris, France

e-mail: Gilles.Billen@upmc.fr

S. Barles

Géographie-Cités, Université Paris 1-Sorbonne, Paris, France the city itself. Indeed, a city depends on surrounding, close or remote territories for its food, fuel, construction and resource consumption, which cannot be solely supplied by its limited territory. Century after century, these supplying areas have in turn been influenced by the city, sometimes deeply structured by their supplying function. These territories, their landscape and the culture of their inhabitants thus also preserve the traces of urban development. The term 'hinterland' was coined to describe these surrounding rural territories shaped by the urban demand for food, energy and materials and by the services offered in return by the city.

Geographers have long drawn circles around cities. Such circles may represent the concentric rings of farming activity devoted to the city's food supply, beginning with market gardening and dairy farming, followed by forestry, cereal production and finally cattle breeding, as depicted by Von Thünen's (1826) idealised economic model based on early nineteenth-century agriculture and transport costs (Fig. 1a). Circles can also represent the rural areas depending on public services offered by the city, thus defining the city's sphere of influence. This representation stresses the above concept of cities exchanging material, energy and information, along strong bidirectional connections, with their hinterland. More recently however, there has been an increasing trend towards considering cities as the nodes of a global network of trade exchanges. On maps, circles around cities are then replaced by lines joining cities, leaving each rural territory as a quasi no man's land crossed by linear infrastructures for the transport of goods, energy and information (Fig. 1b).

This transformation of the geographical representations unveils much about the historical changes in the status of cities and the countryside. In the Western world, where more than $80 \%$ of the population lives in towns, the strong 


$$
\text { a }
$$
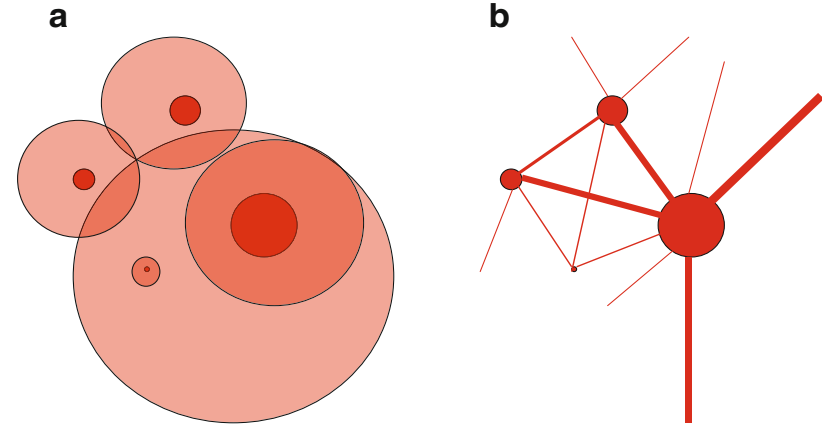

Fig. 1 Sketch of two representations of the spatial relationships of a cities with their hinterland and $\mathbf{b}$ cities considered as nodes of a large exchange network

links that once related urban and rural territories are tending to vanish and be forgotten. The supply of energy increasingly depends on very localised sites of intensive production. The concentration on the industrial raw material and manufacturing sectors has led to wide-ranging world trade supply fluxes from a limited number of production centres, draining the supplying hinterland concept of a large part of its meaning. Yet, supplying cities with a large proportion of its food and drinking water still depends on land-use-based production areas with a vast territorial extension, often in close proximity to the site of urban consumption because of the cost and technical demands of long-distance transport.

Recently, several circumstances have favoured the comeback of territorial approaches to urban supply, together with a renewed interest in urban metabolism (Barles 2010). The issue of raw material and energy resources exhaustion prompted the search for renewable energy and material sources, as well as for saving energy costs by limiting transport distances. The growing concern for supply security and sovereignty is also bringing a territorial analysis of food, material and energy fluxes to the forefront. Some cities are trying to strengthen their links with surrounding agricultural areas in order to limit urban sprawl, maintain greenbelts and develop green frames. Citizen organisations are flourishing, aiming to reconnect local food production and urban consumption, as well as directly controlling the quality of products and the environmental impact of their production, through direct contracts between farmers and groups of concerned consumers. In this context, it was found useful to an interdisciplinary perspective to re-examine the long-term history of material and energy fluxes exchanged between urban communities and their surrounding supplying territories. This was the purpose of an International Workshop held in Paris in September 2009, within two French Research Programmes (PIRVE-Empreintes and ANRConfluent), in order to debate the approaches and results of a number of research groups on large European and North American cities.

\section{Footprint indicators or imprint analysis?}

During the past decade, there have been several indicators proposed to characterise the environmental imprint of cities. Wackernagel and Rees (1996) developed the now classical Ecological Footprint concept based on the comprehensive account of the total productive areas required to sustainably produce the resources consumed by a city, under prevailing world technology, and expressed as additive 'global hectare equivalent' units. Hoekstra and Chapagain (2006) introduced the calculation of the water footprint, expressing the direct and indirect water use associated with urban consumption of commodities. The Carbon Footprint (Wiedmann and Minx 2008) accounts for the overall emission of greenhouse gases resulting from urban activities, while the Nitrogen Footprint (Leach et al. 2012) refers to the corresponding introduction of reactive nitrogen into the biosphere.

The purpose of the papers gathered in this special issue is not to add new indicators to this already long list. Instead, it aims at addressing the following questions:

- Can the supplying area of a large city be specified?

- How has it changed with time? How has the functioning of the supplying territories evolved in parallel with the changes in urban demand?

- In this respect are there different socio-ecological trajectories (Fischer-Kowalski and Haberl 2007) characterising different cities?

From a more contemporary and political perspective, these questions raise two further questions:

- Does the hinterland concept still make sense in the present globalised and interconnected world?

- How can we contextualise the historical trajectory of city-hinterland relationships with the current emerging aspiration to localisation of urban supply?

The material, coming from the Paris conference and gathered in the following pages, although it does not provide definitive answers to these questions, contributes useful examples to situate the debate within its long-term historical and broad geographical perspectives.

\section{Eight cities as case studies}

Eight cities from Western Europe and North America will serve as case studies to illustrate particular issues related to their relationships with surrounding territories: London, 
Paris, Brussels, Vienna, Barcelona, Athens, New York and Providence. The demographic development of these cities during the last 250 years is illustrated in Fig. 2.

\section{City settlement, transport and energy}

The paper by Charruadas (2012, this issue) describes the early stages of the settlement of Brussels, a typical secondgeneration city, and shows how demographic and economic processes linked to agricultural performance in the rural territory before the eleventh century formed the 'cradle' of the city. In a sense, the city's formation can be considered as the imprint of the agricultural growth in the rural territory. Only in a second phase, when Brussels had succeeded in becoming a market centre, did it begin to impose a certain spatial structure and intensification on the rural system. Keene (2012, this issue) reviews the impact of London's demands for food, drink and fuel on the farming systems and specialisation in the regions from which it drew supplies during the period around 1300 when the city reached the peak of its medieval size. In many respects, the patterns observed conform to von Thünen's model, especially in the inner zones surrounding the city

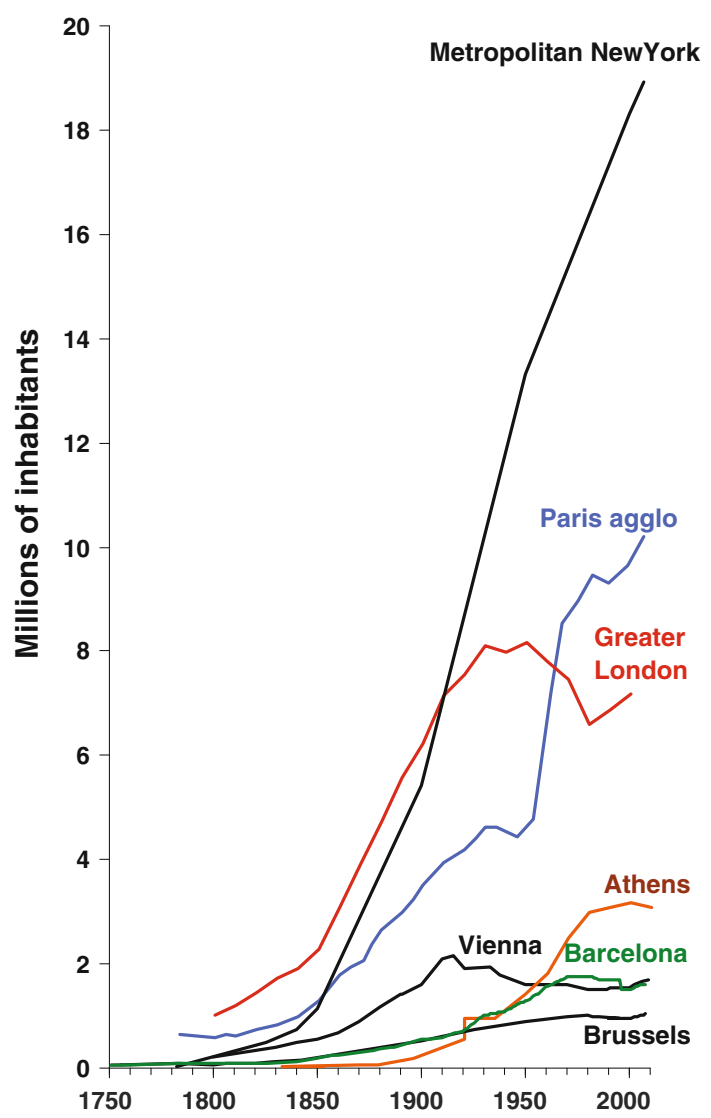

Fig. 2 Demographic development of New York, London, Paris, Athens, Vienna, Barcelona and Brussels during the nineteenth and twentieth centuries (gardening, pasture for livestock, wood fuel and production of the cheaper grains) and in inland areas some distance from the city where extensive farming produced much of the wheat consumed in London. The prominent role of waterways was evidenced from the elongation of these concentric patterns where water rather than land transport was available. The example of nineteenth- and early twentieth-century Vienna, a demographically dynamic, continental city, makes another good case study for addressing the role of water transport in relation to urban supply, resource and land use (Gingrich et al. 2012, this issue). The authors show that the Danube River was the most important route for providing Vienna with fuel wood from remote areas situated upstream, West of the city, while Vienna's surrounding forests were protected by legal regulations to serve as imperial hunting grounds. Only after the railway connection to Northern coal deposits, outside the Danube basin, was established in the 1850s, could Vienna's energy base shift to coal. In spite of important regulations in the 1870s, the Danube lost its importance as a major freight transport route.

The energy supply of Paris during the same period (Kim and Barles 2012, this issue) first underwent a shift from land-use-based biomass to coal without a significant increase in the per capita total energy requirement. Then, after WWII, Paris underwent a further shift to petroleum, natural gas and primary electricity, accompanied by a fivefold increase in the per capita total energy requirement and a considerable increase in supply distances. The local energy provision is currently of minor significance.

The metal needs of a city differ from food and energy requirements in that metals accumulate and form stocks, which can be recycled. The trend in the Paris supply in non-ferrous metal commodities (lead for pipes and later for automobile batteries, zinc for roofs, copper for boilers and electricity) is analysed by Lestel (2012, this issue). Although only limited ore resources are available in France, Paris played a leading role in the development of the non-ferrous industry in the first half of the nineteenth century, with its smelters and transforming factories within the city borders, which covered the Parisian needs. Metal smelting was later banned from the conurbation, and only a small activity of metal transformation into goods remained, until recently. Presently, the last function of the Parisian conurbation in the metal metabolism is to provide waste metal to foundries located outside the French territory.

\section{City Foodshed}

As for food supply, Billen et al. (2012, this issue) show that Paris seems to have remained anchored to a large extent in its traditional hinterland, even though the corresponding rural territory has turned away from its privileged 
relationship with the city and resolutely entered a globalisation dynamic: French agriculture has opened to the world, while $70 \%$ of Paris's needs, surprisingly, remains supplied by its surrounding areas. However, as animal husbandry has been gradually banned from the central Paris basin, now mostly devoted to cereal production, the provision of animal products to Paris mostly originates from the contiguous West and North regions of France, which have specialised in intensive livestock farming largely based on imported soybean from Brazil and Argentina.

North American cities share with European cities the problems of water and food supply from their hinterland, but, because of their much shorter history, the development of railroads and steam-powered water transport allowed food and commodities to be supplied from distant regions at a much earlier stage in their development. Swaney et al. (2012, this issue) describe how New York City's food supply was provided from distant sources as early as the beginning of the nineteenth century, owing to the development of an efficient transportation system linking the city with the fertile areas of central North America first by canals, then railroads and later modern surface and air transport networks.

\section{Urban water imprint}

Water supply is another important aspect of the relationships between a city and its hinterland, which often interferes with other aspects such as food supply. Stergiouli and Hadjibiros (2012, this issue) describe the history Athens's management of water resources and the development of successive water supply infrastructures throughout its long history from the fifth century B.C. until today, with the greater Athens area housing nearly half the population of Greece and controlling a significant amount of the country's water resources, while no serious effort has ever been made to slow down the increase of urban per capita consumption in the city.

These results contrast with those presented by Tello and Ostos (2012, this issue) regarding the evolution of urban water withdrawal and consumption of Barcelona from the eighteenth to the twenty-first centuries. Although they reveal an overall increase in both per capita and total water withdrawn by Barcelona from the Catalan River basins up to a peak reached in 1967-1970, a clear downward trend has occurred since then, mainly driven by less water use by the local economy, a halt in population growth, and the recent emergence of a New Sustainable Water Culture in Catalan society. The observation that a city can achieve better living standards without needing more water, and even consuming less, stands out against the allegation that new transfers from remote basins such as the Ebro or Rhone rivers are necessary.

Swaney et al. (2012) describe how vast territories in relatively close vicinity of New York were managed for the main purpose of providing high-quality drinking water, with sophisticated hydraulic engineering, and, recently, the application of creative governance approaches aimed at reducing diffuse agricultural pollution and acknowledging the value of ecosystem services and the need for wetland protection.

Nixon and Fulweiler (2012, this issue) document the case of Providence (RI), a city that is considered as the cradle of the industrial revolution in the USA, as the first fully mechanised textile factory was settled there as early as 1790 . The authors mainly examine how the development of the city impacted the adjacent coastal marine ecosystem of Narragansett Bay through the release of increasing amounts of human, animal and industrial waste products.

\section{Regional sourcing versus the globalisation debate}

Donaghy (2012, this issue) examines how urban environmental imprints currently outstrip traditional hinterlands because of the strong global connectedness of modern cities linked to the reduction of transport costs and the advances in information and communication technologies. $\mathrm{He}$ also surveys possible responses to these developments, focussing in particular on the critical roles that changes in both behaviour and urban infrastructure systems can play.

Globalisation is indeed at the core of the current debate on the city-hinterland relationships and local re-sourcing of economic activities. The Von Thünen model was conceived in an 'isolated state'. Globalisation has made cities so strongly interconnected as well as so dependent on a limited number of spatially remote, consolidated firms, that the concept of hinterland as described by Von Thünen has become irrelevant in a number of current localities. In the case of the urban supply of energy and most durable consumer goods, the trend to expansion of the supply areas and market internationalisation since the beginning of the industrial era is obvious, with an extreme territorial specialisation and concentration of production activities. The urban imprint of one city on its supplying areas is superimposed on the imprint of so many other cities in the world that privileged territorial relationships no longer exist between the city and the territories which once constituted its hinterland. Cities have become no more than nodes among many others in a network of transactions at the global scale. Any attempt to re-source economic activities seems doomed to failure or to remaining marginal. Yet, with the global depletion of raw material and fossil energy resources, the local exploitation of sometimes huge and 
unexploited urban deposits might rise on the agenda, which could involve new forms of localisation of industrial activities. Similarly, the replacement of fossil fuel or nuclear energy with land-use-based renewable energies might well lead to reconsidering territoriality in energy supply planning.

Contrary to energy and many other commodities, water remains a more locally provided resource: even if the trend towards extension of the supply areas is apparent in some cities such as Athens, as discussed above, water transport for urban supply remains limited to a few hundred kilometres at most. The food issue occupies an intermediate position: the mean food supply distance differs a great deal between different cities in the world, some having made the choice of a distant and globalised market (New York City is an example), others (such as Paris) remaining strongly dependent on much closer supply areas. From the angle of urban-hinterland relationships, the food question therefore gives rise to the strongest territorial issues. Among these, the question of the compatibility between food and drinking water production by the same territories figures prominently, as well as the willingness of an increasing number of urban, concerned consumers to reconnect to more direct, human and healthy food production and distribution modes. We hope that the case studies presented in this special feature will contribute to feeding this already lively debate.

Acknowledgments The papers gathered in this special feature originate from a workshop organised in Paris in September 2009, funded by grants from the Interdisciplinary Research Programme on City and Environment (PIRVE) directed by the French Ministry of Ecology, Sustainable Development, Transport and Housing (MEDDATT) and the CNRS, and the ANR 'Ville Durable' CONFLUENT Programme (ANR 08-VILL-0008/PIRVE). The subsequent work was funded a grant by the Ville de Paris (Paris 2030 Programme) as part of the activities coordinated by the FIRE (Fédération Ile-de-France de Recherche en Environnement) and the PIREN-Seine Programme.

\section{References}

Barles S (2010) Society, energy and materials: the contribution of urban metabolism studies to sustainable urban development issues. J Environ Plan Manag 53:439-455

Billen G, Chatzimpiros P, Barles S, Garnier J (2012) Grain and meat to feed Paris: the changing balance between cereal cultivation and animal farming in the Paris Basin (18th-21st centuries). Reg Environ Change (this issue). doi:10.1007/s10113-011-0244-7

Charruadas P (2012) The cradle of the city: the environmental imprint of Brussels and its hinterland in the high middle ages. Reg Environ Change (this issue). doi:10.1007/s10113-011-0212-2

Donaghy K (2012) Urban environmental imprints after globalization Reg Environ Change (this issue). doi:10.1007/s10113-0110265-2

Fischer-Kowalski M, Haberl E (2007) Socioecological transitions and global change: trajectories of social metabolism and land use. Edward Elgar Publishing, Cheltenham

Freud S (1930) Das Unbehagen in der Kultur. Internationaler Psychoanalytischer Verlag, Vienna

Gingrich S, Haidvogl G, Krausmann F (2012) The Danube and Vienna: urban resource use, transport and land use 1800 to 1910. Reg Environ Change (this issue). doi:10.1007/s10113-0100201-X

Hoekstra AY, Chapagain AK (2006) Water footprints of nations: water use by people as a function of their consumption pattern. Water Resour Manag 21:35-48

Keene D (2012) Medieval London and its supply hinterlands. Reg Environ Change (this issue). doi:10.1007/s10113-011-0243-8

Kim E, Barles S. (2012) The energy consumption of Paris and its supplying areas from 18th century to present Reg Environ Change (this issue)

Leach AM, Galloway JN, Bleeker A, Erisman JW, Kohn R, Kitzes J (2012) A nitrogen footprint model to help consumers understand their role in nitrogen losses to the environment. Environ Develop $1: 40-66$

Lestel L (2012) Non-ferrous metals ( $\mathrm{Pb}, \mathrm{Cu}, \mathrm{Zn})$ needs and city development: the Paris example (1815-2009). Reg Environ Change (this issue). doi:10.1007/s10113-011-0255-4

Nixon SW, Fulweiler RH (2012) Environmental footprints and shadows in an urban estuary, Narragansett Bay, RI (USA). Reg Environ Change (this issue). doi:10.1007/s10113-011-0221-1

Stergiouli ML, Hadjibiros K (2012) The growing water imprint of Athens (Greece) throughout history. Reg Environ Change (this issue). doi:10.1007/s10113-011-0260-7

Swaney D, Santoro R, Howarth RW, Hong B, Donaghy K (2012) Historical changes in the food and water supply systems of the New York City metropolitan area. Reg Environ Change (this issue). doi:10.1007/s10113-011-0266-1

Tello E, Ostos JR (2012) Water flows in Barcelona (1717-2008): turning points in a long-term evolution of water urban metabolism Reg Environ Change (this issue). doi:10.1007/s10113-0110223-Z

Von Thünen JH (1826) Der isolierte Staat in Beziehung auf Landwirtschaft und National Oekonomie. G. Fischer, Jena

Wackernagel M, Rees W (1996) Our ecological footprint: reducing human impact on earth. New Society Publishers, Gabriola Island

Wiedmann T, Minx J (2008) A definition of 'carbon footprint'. In: Pertsova CC (ed) Ecological economics research trends: chapter 1. Nova Science Publishers, Hauppauge, pp 1-11. https://www. novapublishers.com/catalog/product_info.php?products_id=5999 